NASA Technical Memorandum 113178

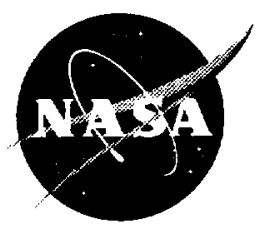

\title{
Electron Affinity Calculations for Thioethers
}

Deley L. Sulton, Michael Boothe, and David W. Ball

Cleveland State University, Cleveland, Ohio

Wilfredo Morales

Lewis Research Center, Cleveland, Ohio

Prepared for the

1998 Annual Meeting

sponsored by the Society of Tribologists and Lubrication Engineers

Detroit, Michigan, May 17-21, 1998

National Aeronautics and

Space Administration

Lewis Research Center 
This report is a formal draft or working paper, intended to solicit comments and ideas from a technical peer group.

This report is a preprint of a paper intended for presentation at a conference. Because of changes that may be made before formal publication, this preprint is made available with the understanding that it will not be cited or reproduced without the permission of the author.

Available from

NASA Center for Aerospace Information 800 Elkridge Landing Road

Linthicum Heights, MD 21090-2934

Price Code: A03
National Technical Information Service 5287 Port Royal Road Springfield, VA 22100 Price Code: A03 


\title{
ELECTRON AFFINITY CALCULATIONS FOR THIOETHERS
}

\author{
Deley L. Sulton, Michael Boothe, and David W. Ball \\ Cleveland State University \\ Cleveland, Ohio 44115 \\ and \\ Wilfredo Morales \\ National Aeronautics and Space Administration \\ Lewis Research Center \\ Cleveland, Ohio 44135
}

\begin{abstract}
Previous work indicated that polyphenyl thioethers possessed chemical properties, related to their electron affinities, which could allow them to function as vapor phase lubricants (VPL). Indeed, preliminary tribological tests revealed that the thioethers could function as vapor phase lubricants but not over a wide temperature and Hertzian pressure range. Increasing the electron affinity of the thioethers may improve their VPL properties over this range. Adding a substituent group to the thioether will alter its electron affinity in many cases. Molecular orbital calculations were undertaken to determine the effect of five different substituent groups on the electron affinity of polyphenyl thioethers. It was found that the $\mathrm{NO}_{2}, \mathrm{~F}$, and I groups increased the thioethers electron affinity by the greatest amount. Future work will involve the addition of these groups to the thioethers followed by tribological testing to assess their VPL properties.
\end{abstract}

Keywords: High temperature tribology; Vapor phase lubrication; Chemistry

\section{INTRODUCTION}

In order to meet the increased thermal stresses that future advanced aircraft will place on currently used esterbased liquid lubricants, new lubricants will have to be developed. If a suitable replacement for ester-based lubricants cannot be found, then one must use a different lubrication method other than the current conventional method of circulating bulk lubricant (stored in a sump) through a lubricating system which contains cooling and filtering elements. Vapor phase lubrication (VPL) may be a viable alternative. 
The basis for the VPL method (Ref. 1) stems from the idea that a "suitable" organic vapor can react to form a solid or semi-solid "friction polymer" compound inside moving (sliding or rolling) concentrated contact areas. Of course, it is expected that the "friction polymer" be highly lubricious and durable to minimize the frictional coefficient and wear of the contacting moving surfaces.

A review of recent literature (Refs. 2 to 5) has revealed that most of the experimental work on VPL has focused on the use of organo phosphate compounds, such as tricresyl phosphate (TCP) and tributyl phosphate, to lubricate wearing surfaces. The experimental results indicated that the phosphate compounds were successful in vapor phase lubricating certain ferrous material, i.e., cast iron, M50 steel (Refs. 3 and 4) but not nonferrous material, i.e., ceramics, Ni-based superalloys (Refs. 3 and 6). It would be highly beneficial if an organic compound could be found to vapor phase lubricate both ferrous and nonferrous components.

A class of polyphenyl thioethers, commonly called C-ethers, possess chemical properties which might make them suitable as vapor phase lubricants. They are thermally and oxidatively very stable under static conditions as shown by isoteniscope measurements and micro-oxidation tests (Ref. 7) They react, however, under boundary lubricating conditions to form insoluble organic polymeric deposits (Refs. 8 and 9). Morales (Ref. 10) investigated the decomposition of $\mathrm{C}$-ethers and concluded that they behaved according to the Goldblatt polynuclear aromatic radicalanion model. In this model, C-ether decomposition, with subsequent formation of organic deposits, is related to the electron affinity (EA) of the C-ether.

A preliminary tribological study (Ref. 11) was conducted at Cleveland State University (CSU) testing a C-ether as a vapor phase lubricant in a pure sliding, reciprocating pin-on-plate apparatus. Better results were recorded when compared to similar runs using TCP. One noted drawback was that temperatures greater than $400^{\circ} \mathrm{C}$ were required for the C-ether to function effectively. A low contact Hertzian pressure (1.2 MPa) was used in this study and it is believed that the $\mathrm{C}$-ether could function at lower temperatures if a higher Hertzian pressure were used. Nevertheless, a vapor phase lubricant should function effectively over both a wide temperature and Hertzian pressure range.

If $\mathrm{C}$-ether EA is a major factor in the formation of friction polymer under boundary lubrication, then perhaps by changing the C-ether's EA we could lower the operating temperature where they begin to function as effective vapor phase lubricants. Adding different substituent groups to the phenyl rings of the C-ether will change its EA. A semi-empirical molecular orbital study was undertaken to asses a preliminary set of substituents which could alter the C-ether's EA. The more promising substituents will then be incorporated into the C-ethers in future work and the resulting substituted $\mathrm{C}$-ethers will be tested under tribological conditions. 


\section{CALCULATIONAL DETAILS}

Optimized structures and total electronic energies of uncharged and radical anionic species were calculated using HyperChem 4.5 on a $133 \mathrm{MHz}$ Pentium-based personal computer. Only AM1 semi-empirical calculations were performed using the Restricted Hartree-Fock (RHF) option, and the Unrestricted Hartree-Fock (UHF) option when needed. The convergence criterion for energy minimization was selected so that the change in total energy on successive iterations was less than $0.001 \mathrm{kcal} / \mathrm{mol}-\AA$. Electron affinities were estimated as the negative of the energy difference between the anion and uncharged molecules; no corrections for electron correlation were made. Trial calculations suggested that energy changes due to thermal effects were negligible, so such corrections were not included in the EA calculations.

Initially, diphenyl sulfide (Fig. 1) was chosen as the model C-ether of interest. The following five substituents were considered in this study: methyl, hydroxyl, fluoro, iodo, and nitro. A single substituent was added to each phenyl ring, and were sequentially attached to carbons in ortho, meta, and para positions with respect to the thio linkage. Substitution was done symmetrically, so that only three isomers for each substituent were studied. No constraints were placed on the geometries of the substituted diphenyl sulfide; conformational differences are expected to have a negligible difference on the total energies of the optimized molecules.

Similar calculations were subsequently performed on three- and four-ringed compounds that are the components of the C-ethers. Figure 1 shows the parent molecules. Substitutions with $\mathrm{CH}_{3}, \mathrm{OH}, \mathrm{F}, \mathrm{I}$, and $\mathrm{NO}_{2}$ groups were made on the outer phenyl groups only, and again were made symmetrically on ortho, meta, and para positions with respect to the ether linkages. Estimates of the EAs were determined on the basis of the change in electronic energies; no correction for electron correlation or thermal energies were made.

\section{RESULTS AND DISCUSSION}

Table I lists the calculated EAs of the diphenyl sulfide derivatives. The parent molecule (indicated by the ' $\mathrm{H}$ ' substituent) has a calculated EA of $+126.2 \mathrm{~kJ} / \mathrm{mol}$. A literature search for its experimental value, for comparison, proved fruitless. Unless other factors (i.e., correlation effects, thermal energy changes, entropy contributions) have an overwhelming influence, the positive EA indicates an energetically-favorable process, Not unexpectedly, the 
$\mathrm{CH}_{3}$ group did not appreciably change the calculated EA, but it was surprising to see the $\mathrm{OH}$ group did not appreciably change the estimated EA either.

Both fluoro and iodo substituents changed the calculated EA by about the same amount, increasing it by about 30 percent. The very strongly electron-withdrawing group, $\mathrm{NO}_{2}$, almost doubled the estimated EA to about $230 \mathrm{~kJ} / \mathrm{mol}$. While there was some effect on the EA due to position of the substituents, it was not consistent and its magnitude was probably lower than the uncertainties in the calculations.

Table II lists the summary of the calculated EAs for the four C-ether components. The reader should note that, with one exception, the only differences in the C-ether components are the types of ether linkages between the phenyl rings. The exception is the compound having only three phenyl rings, 1,3-bis(phenylthio)benzene.

The results in Table II showed interesting patterns. First of all, the predicted EAs of the parent molecules were very similar. As with diphenyl sulfide, the exact position of a substituent did not affect the predicted EA greatly. Finally, within a given substituent, the predicted EA varied very little amongst the four different C-ether molecules. A comparison of Tables I and II showed relative similarities on the affects of the predicted EA with substitution. Both tables revealed that substitution with $\mathrm{a} \mathrm{CH}_{3}$ group changed the EA very little. Substitution with $\mathrm{OH}$ increased the EA only slightly, on average. Substitution with either I or F increased the predicted EA to about $170 \mathrm{kj} / \mathrm{mol}$ on average. Substitution with $\mathrm{NO}_{2}$ increases the predicted EA substantially, but more so for diphenyl sulfide than the C-ethers.

There are two immediate observations from these results. First, the effect of a substituent on the predicted electron affinity was a general one for this family of compounds, and the effect was modified little by substituent position on the phenyl rings. Second, the comparison of Tables I and II showed that the molecule diphenyl sulfide was an acceptable qualitative model for the electron-accepting abilities of $\mathrm{C}$-ethers. There is some quantitative match also, but we hesitate to belabor that issue due to the variances underlying these calculations.

The results of these molecular orbital calculations clearly indicated that the $\mathrm{NO}_{2}, \mathrm{~F}$, and I substituent groups increased the C-ether's EA by the greatest amount, whereas the $\mathrm{CH}_{3}$ and $\mathrm{OH}$ groups altered the C-ether's EA only slightly. Thus, future chemical modification of the C-ethers should center on the incorporation of the $\mathrm{NO}_{2}, \mathrm{~F}$, and I groups onto the phenyl rings of the $\mathrm{C}$-ethers. Properties such as stability, toxicity, etc. must be assessed so any substituted C-ether formulation found to be unreasonably dangerous can be eliminated from VPL tests. Tribological 